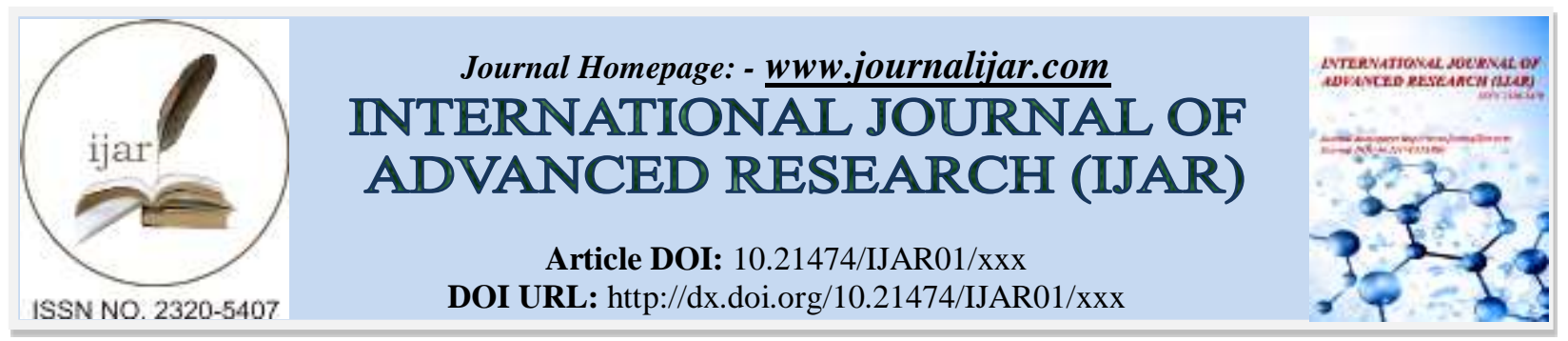

RESEARCH ARTICLE

\title{
TAXONOMIC DESCRIPTION OF THREE SPECIES OF HELIOTHINAE (NOCTUIDAE; LEPIDOPTERA).
}

\author{
"Muddasar, Venkateshalu and Shashank P. R. \\ Department of Entomology, College of Horticulture, Bagalkot, University of Horticultural sciences, Bagalkot - \\ 587104, Karnataka, India.
}

\section{Manuscript Info}

Manuscript History

Received: $x x x x x x x x x x x x x x x x$

Final Accepted: $x x x x x x x x x x x$

Published: $\operatorname{xxxxxxxxxxxxxx}$

Key words:-

Genus, Genitalia, Helicoverpa,

Heliothinae, Noctuidae.

\section{Abstract}

A comprehensive and a comparative taxonomic account of species of the genus Helicoverpa and Heliothis is provided with three species are recognized in the genus $H$. armigera, $H$. assulta and Heliothis peltigera. Morphological characters, wing venation, Genitalic attributes with photographs and illustrations are provided.

Copy Right, IJAR, 2017,. All rights reserved.

\section{Introduction:-}

Heliothinae is a small subfamily of moths in the family Noctuidae. They are found predominantly in semiarid subtropical habitats. The Heliothinae are a cosmopolitan subfamily of noctuid moths, consisting of about 400 species that are most species rich in warm, dry regions of both hemispheres. The larvae attack herbaceous plants, primarily the flowers and fruits. The Heliothinae include several of the world's major crop pests, such as the com earworm and relatives (Helicoverpa) and the tobacco budworm (Heliothis) and relatives, which cause damage amounting to billions of dollars annually.

\section{Materials and methods:-}

The present investigation was undertaken at Department of Entomology, College of Horticulture (COH) Bagalkot during 2015-16. The detailed material and methods during the course of study is presented below

Collection of immatures and rearing: The larvae were collected along with their host plants and were brought to laboratory for further rearing to adults at the Department of Entomology, $\mathrm{COH}$, Bagalkot. The larval cultures were transferred to rearing cages of size $20 \times 20 \times 20 \mathrm{~cm}$ along with its host and were maintained in the laboratory by providing fresh shoots/fruits until they reached pupal stage.

Collection of adults by using light traps: Light source of 200 watt mercury vapour lamp was used with white cloth background in the vegetable fields at Udyanagiri campus $\mathrm{COH}$, Bagalkot. A white cloth of $10 \mathrm{ft}$. $\mathrm{x} 6 \mathrm{ft}$. was hung between two vertical poles with lamp at the centre. The moths which were attracted to light trap were collected.

Processing and preservation of adult moths: The emerged adults in the laboratory or collected from light were killed by using ethyl acetate, pinned through thorax using stainless anticorrosive insect pins (No. 3, 4). The insects were mounted on mounting boards, or on a thermacol, the antenna and wings were stretched properly in order to facilitate identification 
Identification of adult specimens was initially done by picture booking with various online resources, available relevant literature, using the Fauna of British India, Moths of Borneo and Moths of Australia. The identification was confirmed by sending the photographs or specimens of the collected insects to Dr. Shashank P. R. Scientist, IARI, New Delhi and Dr. K. Sivasankaran, Scientist, Entomology Research Institute, Loyola college, Chennai.

\section{Dissection procedure for genitalia:-}

The adults were sorted into male and female based on wing coupling i.e. single frenulum in male and two or three frenular spines in females. Then, the abdomen was detached from thorax and transferred to a test tube containing a $10 \mathrm{ml}$ of 10 per cent caustic potash $(\mathrm{KOH})$ with proper label. Test tube was heated slowly on a spirit lamp for about five minutes till the tissues in the abdomen gets digested and then it was kept for cooling (Brambila, 2009). After cooling, the abdomen was transferred to a watch glass or cavity block containing 10 per cent ethanol and the macerated soft tissues were pressed and removed, scales were removed with the help of Camlin hair brush and transferred to another cavity block with 10 per cent ethanol. After removing of debris and scales the abdomen was cut at the left lateral sides using sharp scalpel/ scissors. Remaining tissues and debris were removed from the internal part of abdomen and a genitalia was separated, later the scales present on genitalia were removed carefully with Camlin hair brush. Aedegus from male genitalia was removed slowly using a sharp forceps without damaging the juxta. Later, vesica was everted from the aedegus by using syringe. Syringe was half-filled ethanol and needle was placed at the opening of aedegus (at the basal portion) and the plunger was pressed to evert entire vesica from aedegus. Aedegus as well as male genitalia was stained with acid fuchsin and female genitalia with chlorazol black for few minutes. The dissected abdomen, genitalia and aedegus were processed by dipping them serially in 30,50 , 70 and 100 per cent absolute alcohol for complete dehydration. After dehydration the abdomen and genitalia were thick, and were mounted on a slide with few drops of euparol and covered with a cover slip of size $40 \mathrm{~mm}$ for abdomen and $20 \mathrm{~mm}$ for genitalia. The prepared slides were labelled properly with the specimen name and date of slide preparation and allowed for drying for about three to four hours, later the slides were placed in hot air oven for about two to three days and were used for further studies.

\section{Results and discussion:-}

During this study three species belonging to two genera were documented and studied the morphological and genital characters. The members of Heliothinae can be distinguished by Small to medium sized with variable but usually boldly patterned or brightly coloured wings. Ocelli present, head scales rough rarely smooth on frons, proboscis naked, labial palpi ascending usually short and tufted. Antenna filiform sometimes with long sensilla, two scale row per segment. Wings heteroneurous, fore wing variable in shape usually triangular, pattern variable usually boldly patterned or brightly coloured lines and often prominent. Hind wing round to square often boldly patterned or brightly coloured. Hind tibial spurs variable. Hind tibial spines often present. Hind tarsal spines present. Uncus is curved and strong with the presence of gnathos. Vinculum shorter the length as that of tegumen. Saccus reduced. Aedeagus tube like vesica bearing numerous cornuti which varies from 12 to 15 .

1a. Epiphysis more prominent (Fig. 1) extended upto tibial tip, fore tibia shorter than basitarsus; mid tibia with piliform scales basally, hind tibia with medial and distally tufted piliform scales; tympanal fold at median

\section{Heliothis peltigera}

1b. Epiphysis less prominent (Fig. 2), fore tibia longer than basitarsus, mid tibia and hind tibia with uniform piliform scales dorsally, tympanal fold on ventral margin. 16

2a. Labial palp $3^{\text {rd }}$ segment shorter than $1^{\text {st }}$ segment; forewing with cross vein discontinuous (broken) (Fig. 3)... Helicoverpa assulta

2b. Labial palp $3^{\text {rd }}$ segment longer than 1st segment; forewing cross vein prominent and acute V-shaped (Fig. 4) Helicoverpa armigera
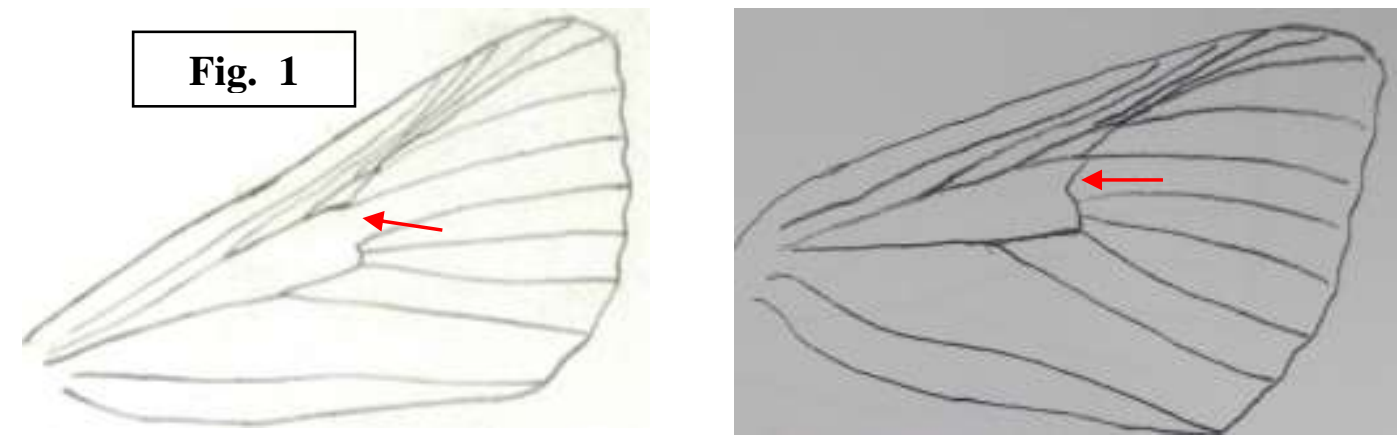

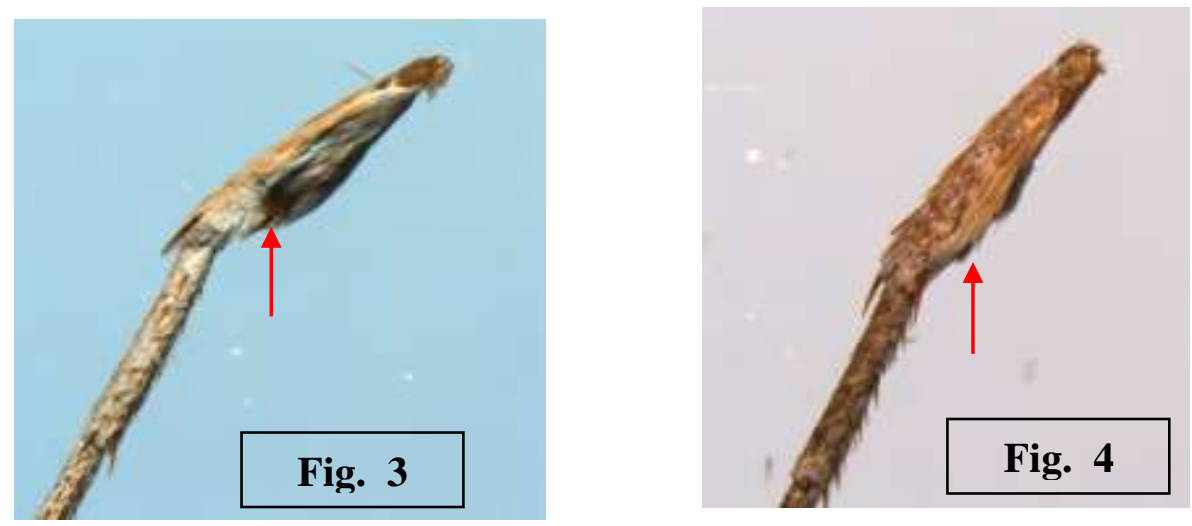

Helicoverpa armigera Hubner, 1805

Heliothis obsoleta Hubner, 1803

Noctua armigera Hubner, 1808

Helicoverpa armigera Hubner, 1808

Heliothis conferta Walker, 1857

Heliothis pulverosa Walker, 1857

Heliothis uniformis Wallengren, 1860

Heliothis guidelli Costantino, 1922

Helicoverpa commoni Hardwick, 1965

Heliothis rama Bhattacherjee and Gupta, 1972

Forewing ochreous with a pale brown, olive and reddish brown tinge at terminal and sub terminal area, and indistinct double waved ante- medial line. A dark speck representing an orbicular spot, with an indistinct curved medial line. Reniform spot distinct. Post medial and sub marginal waved lines, space between them is somewhat darker with a series of dark specks. Hind wing white, veins fuscous, a broad blackish outer border usually with a pale sub marginal central patch. Underside of forewing with orbicular and Reni form stigmata conspicuously black, a broad blackish band beyond the post medial line. The apices of both wings and an outer area of fore wing are pinkish. Females are dark reddish in colour, whereas males are straw yellow coloured (Plate 1).

Head- Vertex rough, scales irregular. Frons rough, scales directed towards middle. Labial palpi equal to the length of eyes, porrect with ventrally piliform scales, $3^{\text {rd }}$ segment less than $2^{\text {nd }}$ segment. Compound eyes with rim and not hairy. Ocelli prominent. Proboscis well developed with dorso lateral cilia. Antennal cilia in males short.

Thorax- Thoracic scales rough, piliform scales. Tympanum with post spiracular hood concave with a lobed extension, tympanal pocket-1 projected laterally, conjuctiva with a narrow attachment and without anterior flap. Spiracle laterally visible and present in a medial cavity. Tympanal fold posterior and sclerite medially folded with digitations. Fore tibia flat with lateral outer extended piliform scales and have a pair of spines. Hind tibia medially tufted, hind tibial outer spur longer than half of the inner, terminal tarsal setae 2.

Wing span $-32-38 \mathrm{~mm}$

Fore wing- with areole. $R_{2}, R_{3}, R_{4}$ and $R_{5}$ from areole. $R_{3}$ and $R_{4}$ stalked and connate. $M_{1}$ arise from upper angle. $\mathrm{M}_{2}$ close to $\mathrm{M}_{3} . \mathrm{M}_{3}$ close to lower angle. $\mathrm{CuA}_{1}$ from lower angle. $\mathrm{CuA}_{2}$ away from the middle of the cell. Disco cellular cross vein prominent and angled. $\mathrm{R}_{1}$ before $\mathrm{CuA}_{2}$ from discal cell,

Hind wing: with 2 frenulum spines in females. Sc and Rs close to each other at the base. $\mathrm{M}_{2}$ absent. $\mathrm{CuA}_{2}$ away from middle of the cell. Disco cellular cross vein vestigial before middle Lower angle and upper angle at equidistance.

Abdomen- scales smooth, abdominal segment 1 with a deep notch dorso laterally. 
Male genitalia- Uncus long, sclerotised curved, pointed and setose dorsally for entire length. Tegumen inverted Vshaped longer than uncus and vinculum V-shaped. Saccus distinct bell shaped two arms of tegumen broad, weakly sclerotised. Vulva long and narrow, ventral margin slightly concave with a row of macro setae and numerous setae at apex of vulva, two basal lobes are present. Juxta weakly sclerotised, rectangular with concave at base. Transtilla indistinct.

Aedegus long, slender, weakly sclerotised narrow towards base. Vesica thrice the length of aedeagus with 12 cornuti and $6-8$ coils, single lobe at the base of vesica.

Female genitalia- corpus bursae, elongate, sclerotised at base and membranous towards apex. Corpus bursae with three signum lines and ductus seminalis longer than the corpus bursae with knot like swellings. Corpus bursae tapering towards base, broader at apex. Ductus bursae small, well sclerotised half the length of ductus bursae. Ostium bursae weakly sclerotised, ostial opening narrow at the base, anterior apophyses is longer than the posterior and spatulate towards apex. Papilla analis small, triangular, weakly sclerotised with macro and micro setae.

Material examined: INDIA: Karnataka: Dharwada, 10 స, 15. xi. 2015, reared on Okra, Muddasar; Bagalkot, Haveli, 16. ix. 2015, reared on Tomato, Muddasar; COHB, 20. ix. 2015, reared on Tomato, Muddasar; 03. x. 2015, light trap, Muddasar. 10 , Dharwada, 10 స̃, 15. xi. 2015, reared on Okra, Muddasar; Bagalkot, Haveli, 16. ix. 2015, reared on Tomato, Muddasar; COHB, 20. ix. 2015, reared on Tomato, Muddasar; 03. x. 2015, light trap.

\section{Helicoverpa assulta Guenee, 1852}

Heliothis separate Walker, 1857

Heliothis temperata Walker, 1857

Heliothis succinea Moore, 1881

Head thorax and wings brownish yellow. Orbicular and reniform prominent and distinct. Sub basal line dark brown, vein $\mathrm{M}_{2}, \mathrm{M}_{3}$ and $\mathrm{CuA}_{1}$ well distinct. Medial line dark brown to black extending from coastal to inner margin. Post medial and sub marginal waved lines with a thick reddish brown border, area between these lines is light with a series of dark specks. Hind wing white, veins fuscous, cross vein between $\mathrm{M}_{1}$ and $\mathrm{M}_{2}$ thick and distinct black in antimedial area. A broad blackish patch extending from terminal portion of wing up to the medial area (Plate 2).

Head- Vertex rough, scales irregular. Frons rough, scales directed towards middle. Labial palpi equal to the length of eyes, porrect with ventrally piliform scales, $3^{\text {rd }}$ segment short. Proboscis well developed with dorso lateral cilia. Antenna with short cilia in males.

Thorax- Thoracic scales rough, piliform. Tympanum with post spiracular hood concave with a lobed extension, tympanal pocket-1 projected laterally, conjuctiva with a narrow attachment and doesn't have anterior flap. Spiracle laterally visible and present in a medial cavity. Tympanal fold posterior and sclerite medially folded with digitations. Fore tibia flat with lateral outer extended piliform scales and have a pair of spines, tibial length shorter than the basitarsus, Hind tibia medially tufted, hind tibial outer spur longer than half of the inner, hind tibia spinose. Terminal tarsal setae 2 .

Wing span - 30-32 mm

Fore wing- with areole. $R_{2}, R_{3}, R_{4}$ and $R_{5}$ from areole. $R_{3}$ and $R_{4}$ stalked and connate less than half the length of $R_{3}$. $M_{1}$ arise from upper angle. $M_{2}$ close to $M_{3}$. $M_{3}$ close to lower angle. $C u A_{1}$ from lower angle. $\mathrm{CuA}$ away from the middle of the cell. Disco cellular cross vein indistinct. $\mathrm{R}_{1}$ before $\mathrm{CuA}_{2}$ from discal cell.

Hind wing: with 2 frenulum spines in females. Sc and Rs stalked at the base. $\mathrm{M}_{2}$ absent. $\mathrm{CuA}$ away from middle of the cell. Disco cellular cross vein indistinct. Lower angle and upper angle at the equidistance.

Abdomen- scales smooth, abdominal segment 1 with a deep notch dorso laterally.

Female genitalia- Corpus bursae oval to round membranous, equal to the length of ductus bursae, three signum lines present one is smaller another two lines are longer. Ductus bursae tubular, membranous with some sclerotised markings. Ductus seminalis $5 \mathrm{X}$ longer than the length of corpus bursae with 8 knots. Anterior apophyses and 
posterior apophyses almost of equal length. Anterior apophyses with a spatulate apex whereas posterior with pointed apex. Papilla analis less sclerotised broad at the base, setose with micro setae.

Material examined: INDIA: Karnataka: Bagalkot, COHB, 3 ㅇ, 20. ix. 2015, reared on Tomato, Muddasar.

\section{Heliothis peltigera Denis and Schiffermuller, 1775}

Noctua peltigera Denis and Schiffermuller, 1775

Yellowish differs from Helicoverpa armigera in being always ochreous. Fore wing with reddish brown patches on costa, one small at ante medial, another above the reniform, which is prominent with grey centre, and a post medial band. A series of black specks at the post medial area and at the marginal area in females. Sub marginal band dark. Underside with reniform prominent and black, orbicular obsolete. Hind wing fuscous with a prominent dark cross vein and dark patch towards the outer margin (Plate 3).

Head- Vertex rough, scales irregular. Frons rough, scales directed towards middle. Labial palpi porrect, equal to the length of eyes. Compound eyes with rim and not hairy. Ocelli prominent. Proboscis well developed with dorso lateral cilia. Antenna short ciliated in males.

Thorax- Thoracic rough piliform scales. Tympanum with post spiracular hood concave with a lobed extension, tympanal pocket-1 projected laterally, conjuctiva with a narrow attachment and doesn't have anterior flap. Spiracle laterally visible and present in a medial cavity. Tympanal fold posterior and sclerite medially folded with digitations. fore tibia flat with lateral outer extended piliform scales and have a pair of spines, tibial length longer than the basitarsus, Hind tibial spinose medially and distally tufted, outer spur longer than half of the inner, Terminal tarsal setae 2 .

Wing span $-36-40 \mathrm{~mm}$

Fore wing- with areole. $R_{2}, R_{3}, R_{4}$ and $R_{5}$ from areole. $R_{3}$ and $R_{4}$ stalked and connate upto $1 / 3^{\text {rd }}$ of $R_{3}$. $M_{1}$ arise from upper angle. $\mathrm{M}_{2}$ close to lower angle. $\mathrm{M}_{3}$ from lower angle. $\mathrm{CuA} 1$ below lower angle. $\mathrm{CuA}_{2}$ away from the middle of the cell. Disco-cellular cross vein distinct.

Hind wing: Hind wing with 2 frenulum spines in females. Sc and Rs anastomosed at the base forming a fork. $\mathrm{M}_{2}$ absent. $\mathrm{CuA}_{2}$ away from middle of the cell. Disco-cellular cross vein indistinct. Lower angle almost equal to upper angle.

Abdomen- scales smooth, first segment deeply notched dorso-laterally.

Male genitalia- uncus long, sclerotised, curved to J-shaped with numerous dorsal setae and an apical spine. Tegumen longer than the uncus and vinculum, Inverted V-shaped with both arms broad and setose. Gnathos membranous, vinculum small U-shaped with a saccus tip like spine at the apex. Vulva well developed and sclerotised costa with numerous setae, ventral margin with few spines, apex of vulva with numerous spines and setae. A small costal process present at the base. Juxta slightly sclerotised, narrow at the base W-shaped. Transtilla distinct and sclerotised.

Aedeagus small elongate tube like, sclerotised at the base. Vesica narrow membranous with a comb like process inside.

Female genitalia- corpus bursae long, membranous with striations, tubular and elongate $4 \mathrm{X}$ larger than the length of ductus bursae with a sclerotised comb like process inside. Three sclerotised signum lines present on the corpus bursae. Ductus bursae small membranous, tubular and sclerotised at the base. Ostium bursae sclerotised. Anterior and posterior apophyses are almost of equal length with spatulate apex. Papilla analis small triangular broad at base, less sclerotised with macro and micro setae.

Material examined: INDIA: Karnataka: Bagalkot, COHB, 3 ô, 17. Xii. 2015, light trap, Akshata, K; 10. Xii. 2015, light trap, Muddasar; 4 , , 15. Xii. 2015, light trap, B. Sc, student's collection. 
The members of this subfamily were characterized by antennae in both sexes are filiform; palpi short, pressed; proboscis well developed; frons convex, sometimes with sclerotized comb; in most genera tibia of all legs armed with spines (Matov et al., 2008). Elongate and flap-like vulvae. Uncus is curved, Vinculum and tegumen of same size in this genus. Saccus is reduced and juxta inverted funnel like. Aedeagus tube like with vesica bearing cornuti. Female genitalia with different shapes of corpus bursae, whereas ductus bursae is often small (Sekhon, 2013).

\section{Generic affinities:}

The genera, Helicoverpa and Heliothis can be distinguished by naked eyes without lashes, palpi porrect, $2^{\text {nd }}$ joint evenly clothed with long hair, fore tibia with a pair of terminal spines, mid and hind tibia spined (Hampson, 1894). The species $H$. armigera and $H$. assulta can be differentiated by wing pattern, length and shape of corpus bursae for the collected specimens i.e. the species $H$. armigera is having reddish brown body colouration, orbicular and reniform spot indistinct and shape of corpus bursae is elongated and oval shaped, whereas the species $H$. assulta is having orange yellow body colouration, orbicular and reniform spot prominent and corpus bursae circular and not much elongated as compare to $H$. armigera.

The species, Heliothis peltigera differs from $H$. armigera in being ochreous, under side of the forewing with reniform spot prominent and black but orbicular obsolete, whereas in $H$. peltigera having underside of forewing with the orbicular and reniform conspicuously black (Hampson, 1894).

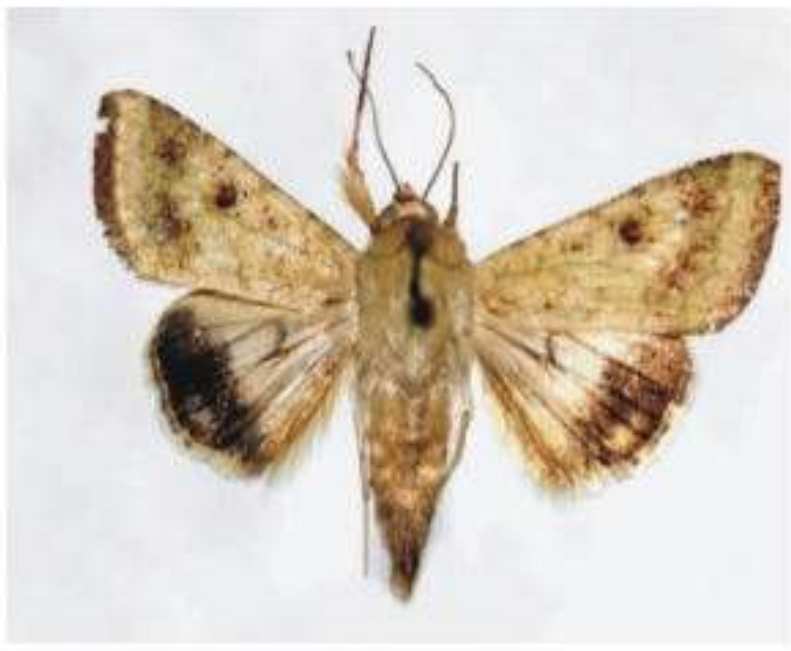

A. Male

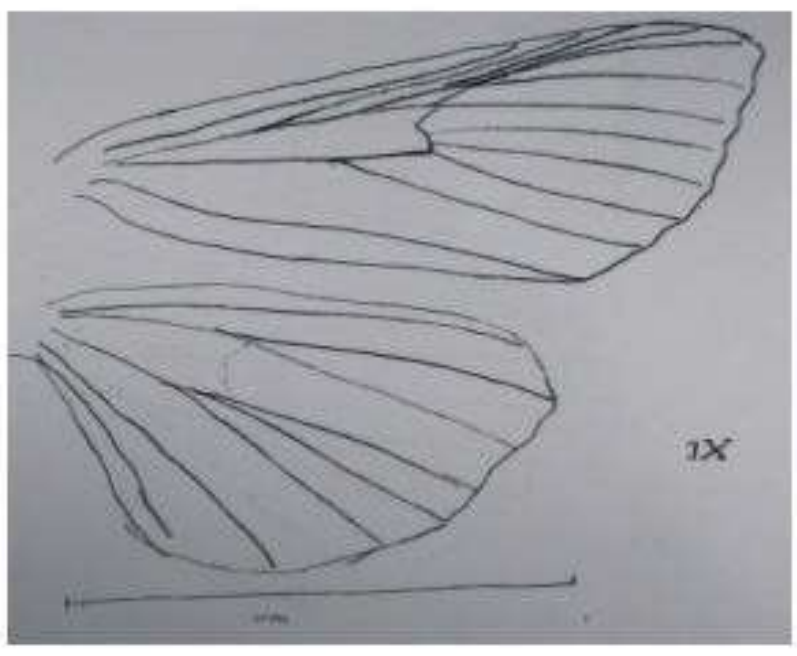

C. Wing venation

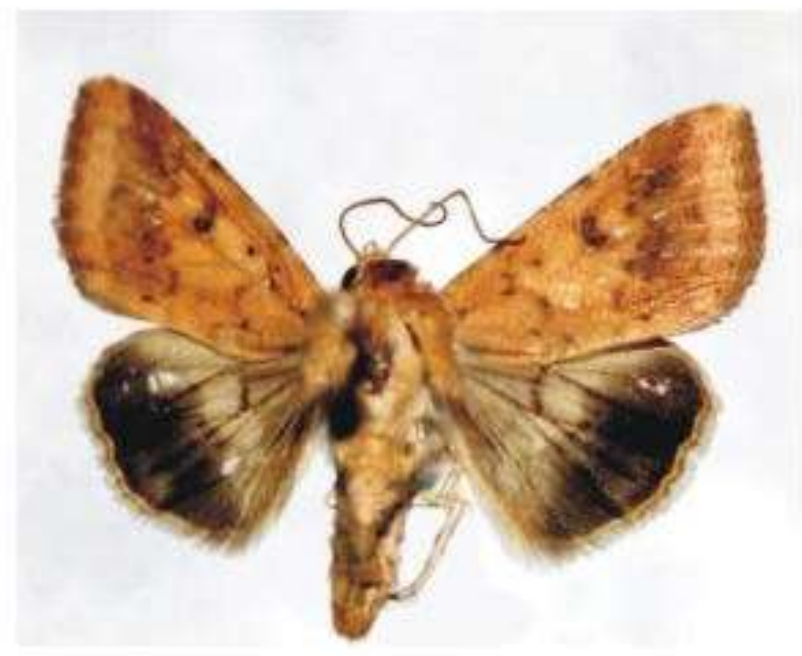

B. Female

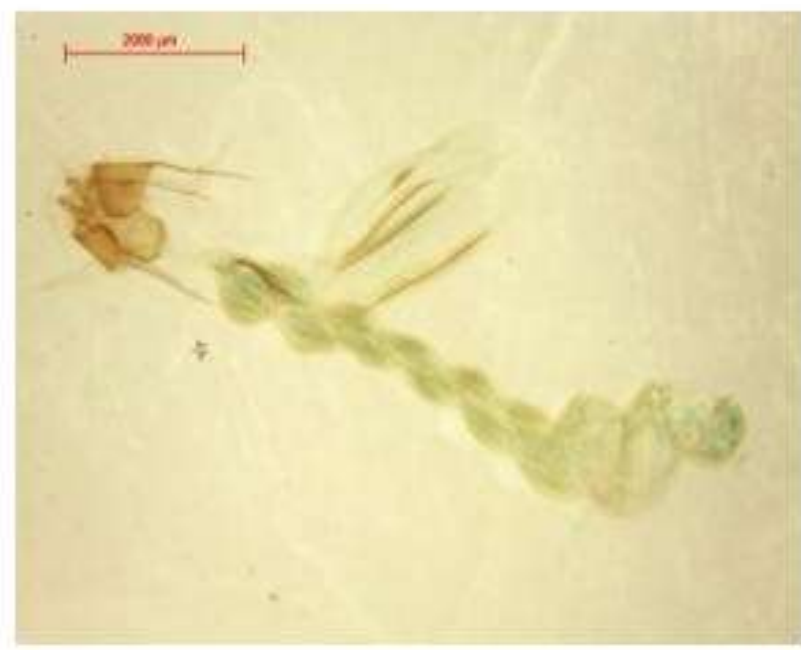

D. Female genitalia 


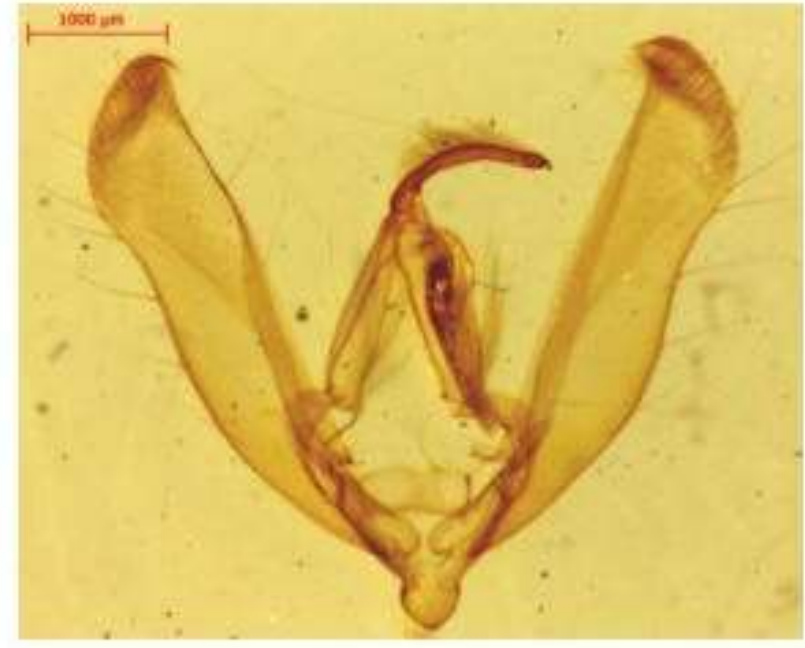

E. Male genitalia

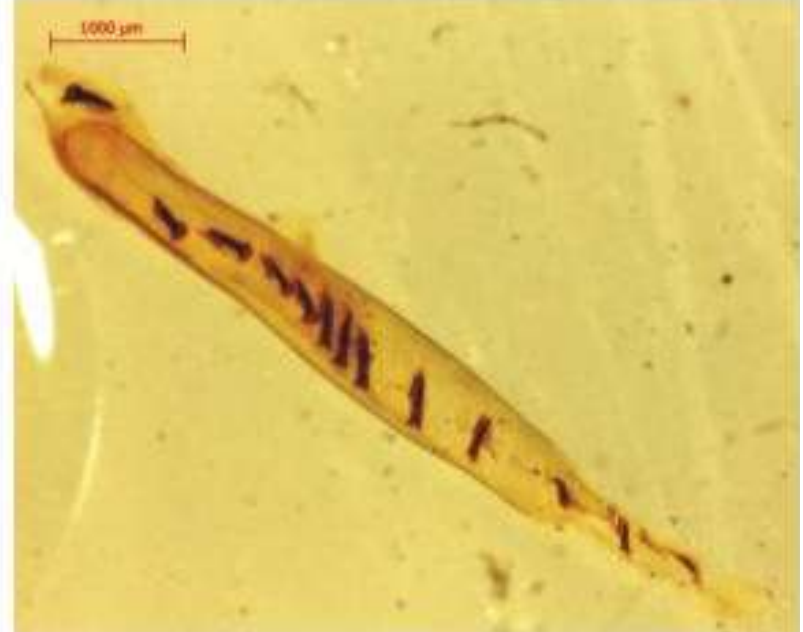

\section{F. Aedeagus}

Plate 1:- Helicoverpa armigera (Hubner, 1805)

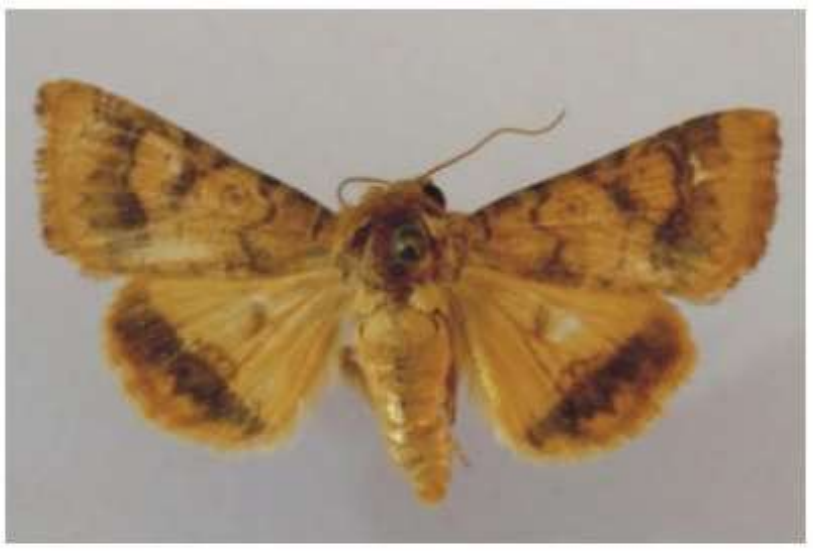

A. Female

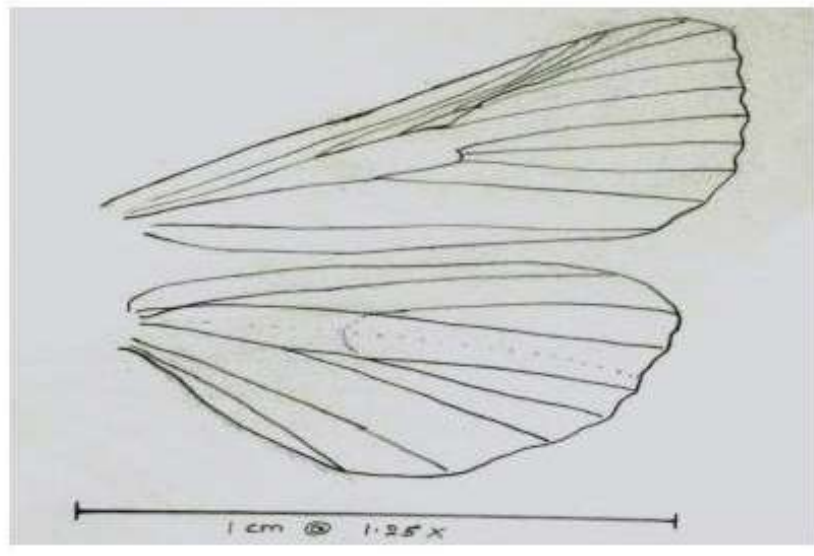

B. Wing venation

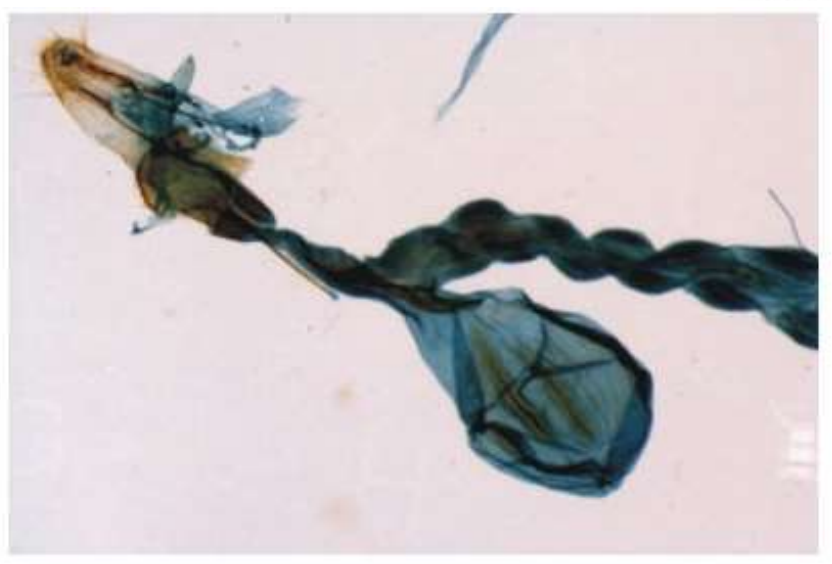

C. Female genitalia

Plate 2:- Helicoverpa assulta (Guenee, 1852) 


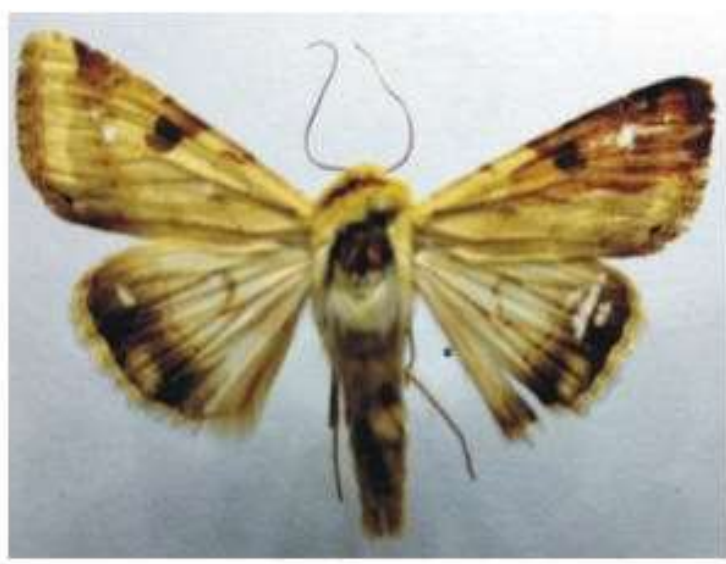

A. Male

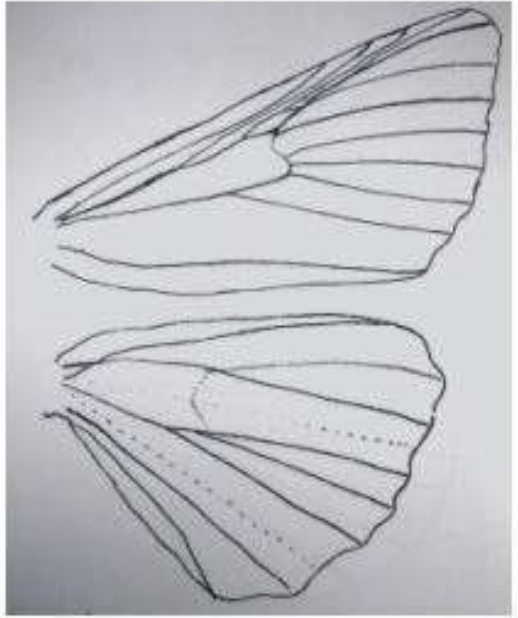

C. Wing venation

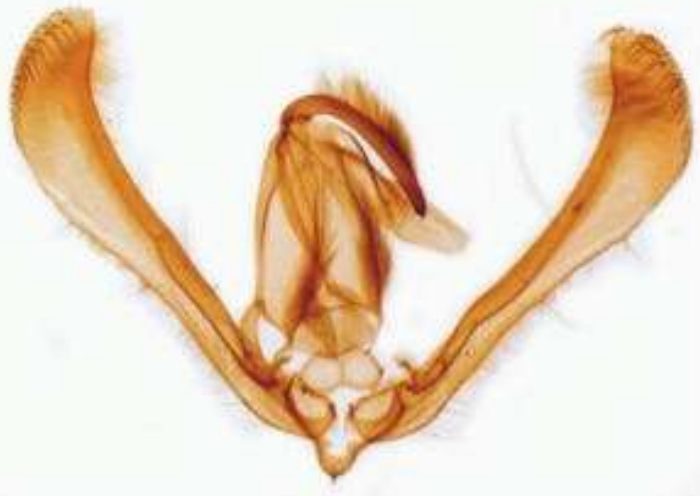

E. Male genitalia

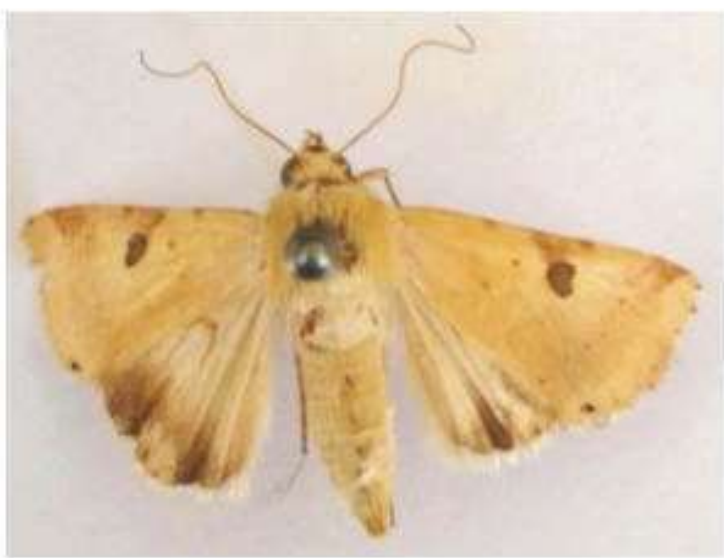

B. Female

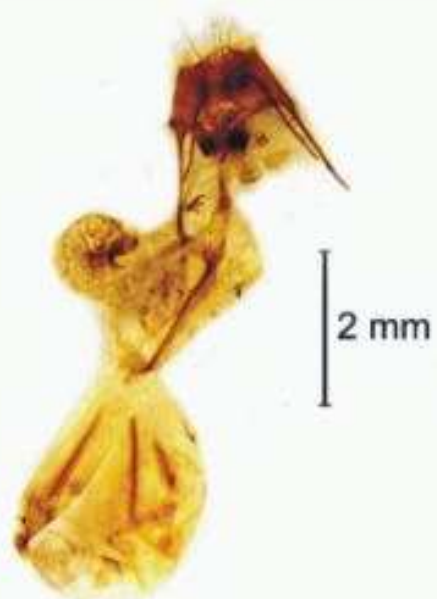

D. Female genitalia

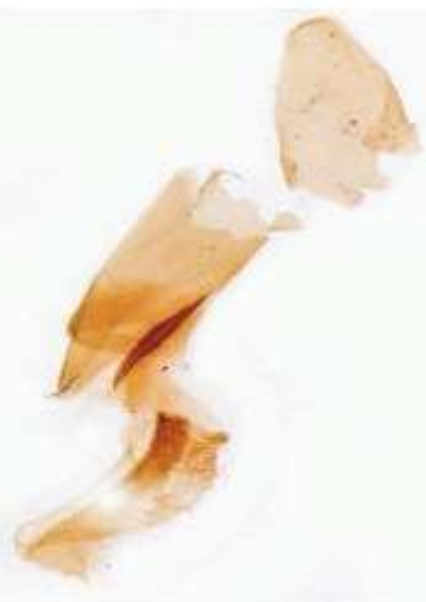

F. Aedeagus

Plate 3:- Heliothis peltigera (Denis and Schiffermuller, 1775) 


\section{Acknowledgement:-}

The authors are thankful to Dr. Shashank, Pathour, Scientist, Dept. of Entomology, IARI, New Delhi. for helping in identification and dissection of genitalia.

\section{References:-}

1. Brambila, J. 2009, Instructions for dissecting male genitalia of Helicoverpa (Lepidoptera: Noctuidae) to separate $H$. zea from $H$. Armigera. USDA-APHIS-PPQ.1-16.

2. Hampson, G. F. 1894, Fauna of British India, Moths, 2: 160-609, 3: 1-107. Taylor and Francis Ltd., London.

3. Khiaban, N. G. M. Z., Nejad, H. I. K., Hejazi, M. S., Mohammadi, S. A. and Sokhandan, N. 2010, A geometric morphometric study on the host populations of the Pod Borer, Helicoverpa armigera (Hübner) (Lepidoptera: Noctuidae) in some parts of Iran. Munis Entomology and Zoology. 5 (1): 140-147.

4. Matov, A., Zahiri, R. and Holloway, J. D. 2008, The Heliothinae of Iran (Lepidoptera: Noctuidae). Zootaxa. 1763: $1-37$.

5. Pogue, M. G. 2004, A New Synonym of Helicoverpa zea (Boddie) and differentiation of adult males of H. zea and $H$. armigera (Hubner) (Lepidoptera: Noctuidae: Heliothinae). Annals of Entomological Society of America. 97 (6) : 1222-1226.

6. Sekhon, C. K. 2013, Taxonomic significance of external genitalia in family Noctuidae (Noctuoidea: Lepidoptera). PhD (Dept. of Zoology and Environmental Science) Thesis, Punjab University pp. 33-144. 